\title{
A reactive transport model for evaluating the long-term performance of stainless steels in concrete
}

\author{
M. Boulfiza \\ Department of Civil Engineering, University of Saskatchewan, Canada
}

\begin{abstract}
One significant challenge facing the world today is the decay of infrastructure. A major component of infrastructure decay is the degradation of bridges and highways due to corrosion of the embedded reinforcing steel. This problem has prompted the development of a variety of alternative strategies for increasing the service life of reinforced concrete structures exposed to harsh environments. Over the last two decades, many advanced metallic and non-metallic materials have been developed for withstanding severe corrosion typically encountered in concrete bridge decks. However, adoption of these materials by industry has fallen far short of initial expectations, due in a large extent to a lack of tools to evaluate their long term in-service performance. At present, very little reliable information is available for evaluating the corrosion performance of advanced reinforcement materials available in the market for bridge decks over the entire service life of the structure. Based on first principles, a comprehensive reactive transport model is proposed in this study for predicting the occurrence of general and localized corrosion in concrete bridge decks. Preliminary results show excellent agreement with experimental data under various environmental conditions.
\end{abstract}

Keywords: corrosion, stainless steel, concrete, bridge deck, reactive transport, modelling, service life.

\section{Introduction}

The cost of protecting and restoring concrete structures worldwide is a large and growing problem $(>\$ 100$ billion/yr). A major component of infrastructure decay is the degradation of bridges and highways due to corrosion of the embedded 
reinforcing steel. This problem has prompted the development of a variety of alternative strategies for increasing the service life of reinforced concrete structures exposed to harsh environments. However, adoption of these materials by industry has fallen far short of initial expectations, due in large extent to a lack of tools to evaluate their long term in-service performance. At present, no technically sound procedure is available for evaluating the corrosion performance of advanced reinforcement materials available in the market for bridge decks over the service life of the structure.

Reinforcing steel in concrete is initially surrounded by a highly alkaline $(\mathrm{pH}>$ 13) pore solution. At this high $\mathrm{pH}$, a thin protective layer of ferric oxide is formed on the surface of the steel. Disruption of the protective layer of ferric oxide takes place when the concentration of chloride ions in the vicinity of the rebars exceeds a critical threshold value. Based on first principles, a comprehensive model is proposed in this study for predicting the occurrence of localized corrosion which is known to govern the corrosion behavior of most reinforcing materials in chloride laden environments. Pitting Corrosion (localized) is assessed by calculating the corrosion and repassivation potentials as a function of pore water chemistry and exposure conditions for two stainless steels (304 and 316) and compared with carbon steel. The ingress of chloride ions and the amount of the various aqueous species available in concrete along the depth of concrete cover are calculated using a Pitzer-based reactive transport model which considers all possible chemical interactions with the concrete solid phases and pore water solution.

\section{Mathematical model}

The ability to understand, and, therefore, to predict the onset and subsequent evolution of corrosion in concrete requires the knowledge of: flow and transport processes; chemical interactions between dissolved constituents in the pore solution and the solid phases (concrete and steel reinforcement); as well as coupling between the transport and the chemical processes. Flow and mass transport in the presence of chemical reactions, usually known as reactive transport plays a key role in a variety of problems that may face the bridge engineer who deals with the design and management of structures. Reactive transport processes range from relatively simple approaches, such as solving the transport equation with an appropriate retardation term, to the simulation of complex, multispecies models that couple transport with different types of chemical reactions. The model proposed in this study belongs to this latter class.

A reactive transport model for chlorides ingress and carbonation in concrete has been extended to include corrosion modeling of high performance reinforcing steels. This model deals with transport of carbon dioxide and chloride ions in the presence of chemical reactions. A detailed description of the mathematical model at the core of the simulations in this study has been presented in earlier papers $[1,2]$ and only the salient features of this model will be reviewed here. 
At the core of this model lies the diffusion-reaction equation, which can be written as

$$
\nabla . \phi D \nabla c_{i}+\phi S_{i}=\frac{\partial \phi c_{i}}{\partial t}
$$

in which $c_{i}$ denotes the concentration of the $i^{\text {th }}$ species, $S_{i}$ represents the source (or sink) term (i.e. the change in mass due to chemical reactions) of the $i^{\text {th }}$ species per unit volume of solution, $D$ denotes the coefficient of molecular diffusion in concrete and $\phi$ denotes the porosity. In the above equation the mass of species are increased or destroyed in the source term by a number of mechanisms depending on the problem being considered [3]. These mechanisms may include both homogeneous and heterogeneous reactions. Homogeneous reactions, refer to processes that occur within the aqueous phase itself while other fluid phases present in the void space and the solid matrix are not involved. Heterogeneous reactions, on the other hand, refer to processes that involve interactions between components in the aqueous phase and constituents of the solid phase, or transfer across interphase boundaries within the void space. Examples include reactions between aqueous species and solid phases in concrete and reinforcement. Reactions of either type that contribute to the overall source term $S_{i}$ may be described by using equilibrium or kinetic models [2, 3]. In equilibrium models the concentrations of the multiple species are simultaneously adjusted within the aqueous phase in accordance with equilibrium relationships and mass balance constraints. Such models are appropriate when the rates of reactions are relatively rapid (in comparison with other transport and transformation mechanisms). For example, equilibrium models are appropriate for the description of carbonation or chlorides binding using ion exchange theory. In other situations, when reaction rates are relatively slow, like in the case of corrosion, kinetic models become necessary.

The mass balance and mass action expressions are used to determine how the masses of different chemical elements in an aqueous system, represented as components, are distributed among various species that may be present. For corrosion problems, one needs to explicitly account for redox reactions which involve the exchange of valence electrons between reactants and products. An understanding of redox processes is essential for predicting the onset and evolution of corrosion because the different redox states exhibited by an element can behave very differently from one another. The rates of redox reactions involved in corrosion problems are notoriously slow. Typically, this is because redox reactions involve breaking relatively strong covalent bonds.

Thermodynamics suggests that systems that are in a non-equilibrium state will try to achieve thermodynamic equilibrium. Typical electrochemical reactions involved in corrosion tend to proceed slowly toward equilibrium, and concepts of chemical kinetics must be invoked to characterize how fast the reaction is moving towards equilibrium conditions. A way to characterize corrosion has been through polarization curves and the associated potentials and current densities $[4,5]$. Although, most electrochemical reaction rates are usually represented by current densities, it is always possible to convert corrosion rates 
to $\mathrm{mm} /$ year using simple formulas. It is worth remembering that kinetic expressions are, generally, empirical in nature, and must be determined from experimental measurements. A model, based on the use of experimentally measured repassivation potentials and calculated corrosion potentials, is used here for predicting the long-term performance of various alloys in chloride-laden environments. If the corrosion potential is above the repassivation potential, then localized corrosion initiates.

A two-step approach is used for coupling of the source term in the mass balance equation with the chemical and electrochemical reaction equations governing the interaction of the pore water solution with the concrete solid phases as well as the reinforcement alloys. This approach involves the separate solution of the transport and chemical reaction equations over small times steps without iteration between the two.

\section{The concrete environment}

Cement paste is the product of hydration reaction of the constituents of cement. When cement is exposed to water, a series of reactions, called hydration of cement, occur between cement constituents and water. Both calcium silicates $\left(C_{3} S\right.$ and $C_{2} S$ ) combine with water to form gel-like calcium silicate hydrate (C$\mathrm{S}-\mathrm{H})$ and calcium hydroxide $(\mathrm{CH})$. A portion of the $\mathrm{Ca}(\mathrm{OH})_{2}$ is consumed during the hydration of the other constituents of Portland cement, $C_{4} A F$ and $C_{3} A$. When practically all gypsum has been consumed the hydration reactions of $C_{4} A F$ and $C_{3} A$ produce AFm phases [6]. The minerals of these AFm phases are anionic clay minerals, which have positively charged main layers. Anions incorporated between the layers balance the charge on the main layers. Water molecules are also incorporated into the interlayer. These phases crystallize as thin pseudo-hexagonal plates, composed of distorted portlanditelike octahedral layers, in which one third of the $\mathrm{Ca}^{2+}$ sites are occupied by $\mathrm{Al}^{3+}$ or $\mathrm{Fe}^{3+}$. The substitution of $\mathrm{Al}^{3+}$ or $\mathrm{Fe}^{3+}$ for $\mathrm{Ca}^{2+}$ generates the net positive charge in the octahedral layers, and this substitution always occurs in a stoichometric 2:1 ratio. In addition to anions, the inter-layer contains water molecules, and its water content varies with the type of anion. The inter layer anion can be easily exchanged.

Reinforcing steel in concrete is initially surrounded by a highly alkaline $(\mathrm{pH}>$ 13) pore solution [6]. At this high $\mathrm{pH}$, a thin protective layer of ferric oxide is formed on the surface of the steel. Disruption of the protective layer of ferric oxide takes place when the concentration of chloride ions in the vicinity of the rebars exceeds a critical threshold value [7]. Not all of the chloride ions, which penetrate the concrete, remain free in the pore solution. Some of the ions get bound to the hydration products through a chemical reaction to form calcium chloroaluminate hydrate (Friedel's salt) while others get adsorbed to the various hydrates of cement. Thus, only a portion of the chloride ions remains free. It is 
this latter one that is responsible for causing damage to the concrete structures by corroding rebars. Table 1, provides a description of a typical concrete pore water solution.

Table 1: $\quad$ Ions in initial concrete pore water solution.

\begin{tabular}{|l|c|c|}
\hline \hline $\mathbf{H}_{2} \mathbf{O}$ & 53.613 & $\mathrm{~mol} / 1$ \\
\hline $\mathbf{N a}^{+\mathbf{1}}$ & 0.185 & $\mathrm{~mol} / 1$ \\
\hline $\mathbf{K}^{+\mathbf{1}}$ & 0.2665 & $\mathrm{~mol} / 1$ \\
\hline $\mathbf{C a}^{+\mathbf{2}}$ & $1.25 \mathrm{E}-03$ & $\mathrm{~mol} / 1$ \\
\hline $\mathbf{S O}_{4}{ }^{-2}$ & 0.028627 & $\mathrm{~mol} / 1$ \\
\hline $\mathbf{A l}(\mathbf{O H})_{4}{ }^{-1}$ & $8.00 \mathrm{E}-05$ & $\mathrm{~mol} / 1$ \\
\hline $\mathbf{O H}^{-1}$ & 0.42797 & $\mathrm{~mol} / 1$ \\
\hline
\end{tabular}

The lack of a sound and comprehensive explanation of the mechanisms controlling changes in the pore solution chemistry due to chlorides binding and carbonation in cement-based materials has led to difficulties in predicting the effect of pore solution chemistry on the corrosion behaviour of rebars inside the concrete. Based on the concepts of ion-exchange theory, a recently developed mechanistic model has proven to be very effective in predicting the effects of temperature and carbonation on the evolution of the concrete pore water solution, especially the binding of free chlorides and release of bound chlorides [2]. A very brief description of the model is provided here.

Chemical binding of chlorides is the result of chemical reactions between chloride ions and certain cement hydration products. The final product of chemical binding of chloride ions is Friedel's salt (3CaO. $\mathrm{Al}_{2} \mathrm{O}_{3} \cdot \mathrm{CaCl}_{2} \cdot 10 \mathrm{H}_{2} \mathrm{O}$ ), which is another AFm phase and its composition is $\left[\mathrm{Ca}_{2} \mathrm{Al}(\mathrm{OH})_{6} \cdot 2 \mathrm{H}_{2} \mathrm{O}\right]^{+} \cdot \mathrm{Cl}^{-}$. The ion exchange mechanism, assumed in this study, describes chlorides binding as a replacement of hydroxide ions present in the interlayers of hydroxy AFm phase by chloride ions present in the pore solution. This ion exchange mechanism leads to the formation of Friedel's salt as expressed in the following reaction,

$$
\mathrm{R}^{+}-\mathrm{OH}^{-}+\mathrm{Cl}^{-} \rightarrow \mathrm{R}^{+}-\mathrm{Cl}^{-}+\mathrm{OH}^{-}
$$

where $\mathrm{R}$ is the principal layer of hydroxy $\mathrm{AFm},\left[\mathrm{Ca}_{2} \mathrm{Al}(\mathrm{OH})_{6} \cdot 2 \mathrm{H}_{2} \mathrm{O}\right]^{+}$. The equilibrium constant for eqn (2) is given by:

$$
K_{C l / O H}=\frac{\{R-C l\}\left\{\mathrm{OH}^{-}\right\}}{\{R-O H\}\left\{C l^{-}\right\}} ; \text {Braces in the equation denote activities. (3) }
$$




\section{Corrosion performance of various alloys in bridge decks without overlays}

The case study explored here involves three different reinforcing steels (carbon steel, stainless steel 304, and stainless steel 316) embedded in a typical bridge deck without overlays. Bridge decks without overlays use conventional concrete without any additional protection on the top surface of the deck (Figure 1). As shown in Figure 1, typical nominal dimensions for the steel reinforced deck include an overall height of $250 \mathrm{~mm}, 70 \mathrm{~mm}$ top cover and $50 \mathrm{~mm}$ bottom cover.

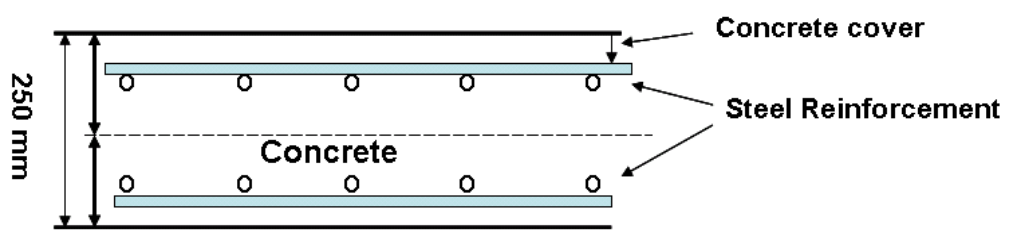

Figure 1: Schematic representation of a bridge deck without overlay.

Service life prediction has emerged, over the last few years, as a major task in the design of concrete structures. Although chloride ions in concrete do not directly cause severe damage to the concrete, they initiate and contribute to the corrosion of steel reinforcement in the structures, when the chlorides concentration at the surface of rebars reaches a threshold level. The formation of rust is associated with large volume expansion which may result in cracking, spalling, and delamination of the concrete cover and in the case of severe corrosion reduces the load-carrying capacity of structures due to a reduction of the cross-sectional area of reinforcement. In cold countries, use of de-icing salt on roads and bridges in winter causes premature deterioration of structures.

Corrosion of reinforcing steel in concrete is generally modeled in two stages. The first stage, known as the corrosion initiation time, represents the time period needed by chloride ions penetrating from the surface to reach a threshold concentration at the rebar level for corrosion to initiate. The second stage, known as active propagation time, is the time from the onset of corrosion until the end of the functional service life for concrete bridge decks due to delamination, spalling, deformation and excessive cracking of the concrete.

It is worth noticing that the numerical model used in this study calculates both the initiation period as well as the corrosion rates during the propagation stage without attempting to determine the time to cracking and spalling and their subsequent effects on the corrosion process. Time to cracking and spalling has often been used considered as the end of the useful life of the bridge deck, time at which concrete cover and the top reinforcement would typically need to be replaced. However, this should not be too hard to establish based on the computed corrosion rates. Indeed, having corrosion rates as a function of time, one could estimate the corrosion depth (loss of reinforcement cross section) and the associated pressure (generated by the change in volume of corrosion 
products) that would develop on the concrete cover as a function of time. Once a critical pressure is reached, cracking and spalling will occur. Table 1, provides a description of the alloys investigated in this study. Although a relatively long history of field performance is available for carbon steel, very little historical data about the field performance of high performance steels like the considered alloys is still lacking. Hence, the need for mechanistic approaches, such as the one proposed in this study, for predicting their long term performance under realistic field condition scenarios.

Table 2: Composition of the reinforcement alloys considered.

\begin{tabular}{c||cccccc}
\hline \hline Alloy & $\begin{array}{c}\text { Fe } \\
(\mathbf{w t} \%)\end{array}$ & $\begin{array}{c}\mathrm{C} \\
(\mathbf{w t} \%)\end{array}$ & $\begin{array}{c}\mathrm{Mn} \\
(\mathbf{w t} \%)\end{array}$ & $\begin{array}{c}\mathbf{C r} \\
(\mathbf{w t} \%)\end{array}$ & $\begin{array}{c}\text { Ni } \\
(\mathbf{w t} \%)\end{array}$ & $\begin{array}{c}\text { Mo } \\
(\mathbf{w t} \%)\end{array}$ \\
\hline \hline Carbon Steel & 98.50 & 0.50 & 1.00 & - & - & - \\
\hline Stainless 304 & 71.90 & 0.10 & - & 19.00 & 9.00 & - \\
\hline Stainless 316 & 66.90 & 0.10 & - & 17.00 & 13.00 & 3.00 \\
\hline \hline
\end{tabular}

Concrete quality and concrete cover thickness, two of the most widely used strategies for mitigating the effect of chlorides on the corrosion performance of the considered steels would be investigated here. The surface chloride concentration on bridge decks depends on the environment and amount of deicing salt application on in winter. Chloride concentration values ranging from 1 to $19 \mathrm{~kg} / \mathrm{m}^{3}$ have been reported in the literature [1,6,7]. A surface chloride concentration of $13 \mathrm{~kg} / \mathrm{m}^{3}$, which corresponds to a relatively severe chloride environment, is used here for the numerical simulations.

\subsection{Effect of concrete cover thickness}

Three cover thicknesses $(50 \mathrm{~mm}, 70 \mathrm{~mm}, 90 \mathrm{~mm})$ are considered to investigate the potential benefit of using thicker concrete covers on the corrosion response of the various alloys considered. Figure 2a) shows the faster build-up of chlorides at the rebar location as the cover thickness is reduced. As can be seen in Figure 2b) and Figure 2c), only a marginal improvement in corrosion rates is achieved by using stainless steel 304 instead of carbon steel. However, a substantial improvement in pitting corrosion rate reduction is achieved by using stainless steel 316 instead of carbon steel. The change is so significant that a different scale than the one used with stainless 304 and carbon steel had to be used in order to be able to appreciate the evolution of corrosion rates in the case of stainless 316 .

\subsection{Effect of concrete quality}

The effect of concrete quality as measured by the diffusion coefficient is investigated in this section. An effective chloride diffusion coefficient of $1.0 \times 10^{-11} \mathrm{~m}^{2} \mathrm{~s}^{-1}$ is used to represent a low quality concrete, a diffusion coefficient of $5.0 \times 10^{-12} \mathrm{~m}^{2} \mathrm{~s}^{-1}$ is used to represent a medium quality concrete, whereas 
$1.0 \times 10^{-13} \mathrm{~m}^{2} \mathrm{~s}^{-1}$ is used to represent a high quality concrete. Figure 3(a) shows that concrete quality can have a tremendous impact in limiting the accumulation of chlorides at the top layer of steel reinforcement. A high quality concrete (Do = $1.0 \times 10^{-13} \mathrm{~m}^{2} \mathrm{~s}^{-1}$ ) would lead to a very slow build-up of chlorides at the reinforcement level, which in turn translates into lower pitting corrosion rates. As can be clearly seen from Figure 3(b) and Figure 3(c), only a marginal benefit would be achieved by using stainless 304 instead of carbon steel in conjunction with this mitigation strategy. Figure $3(\mathrm{~d})$, on the other hand, shows that a substantial improvement would be achieved by using stainless 316 instead of stainless 304 or carbon steel.
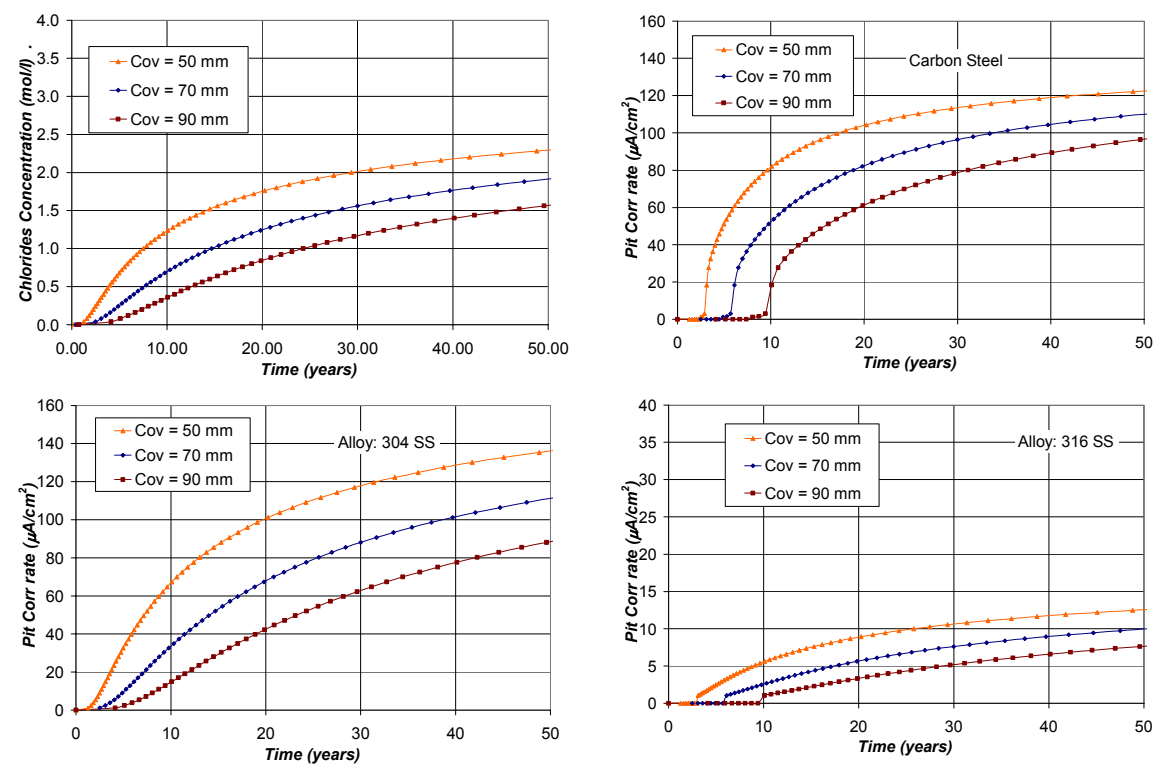

Figure 2: Effect of concrete cover thickness on (a) the chlorides accumulation at the top reinforcement location and (b), (c), (d) the pitting corrosion rates of the various steel reinforcements used.

\section{Conclusions}

The following conclusions can be drawn:

1. Based on first principles, a comprehensive reactive transport model is proposed in this study for predicting the ingress of chloride ions and subsequent occurrence of localized (pitting) corrosion in concrete bridge decks.

2. The model can predict both the corrosion initiation time and the corrosion rates during the propagation period prior to concrete cracking and spalling, which is usually considered the end of the useful life of a bridge deck since repairs would be required 


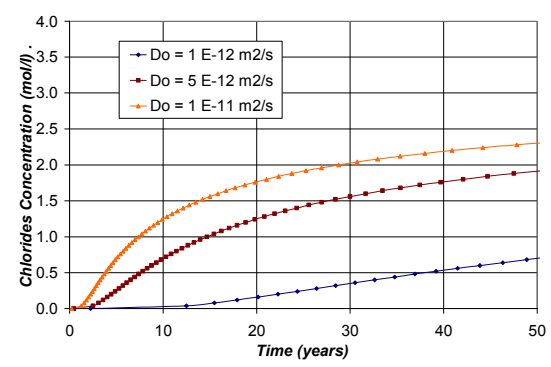

a)

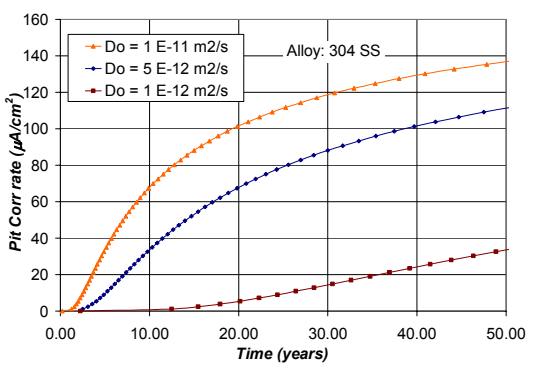

c)

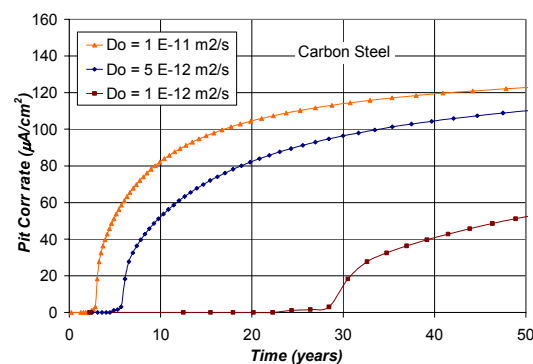

b)

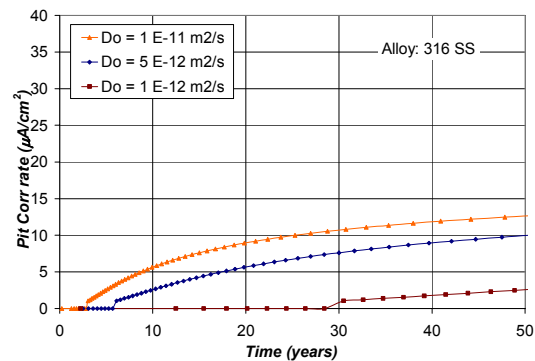

d)

Figure 3: Effect of concrete quality on a) the chlorides accumulation at the top reinforcement location and $b$ ), c), d) the pitting corrosion rates of the various steel reinforcements used.

3. The relative performance of various corrosion mitigation design strategies has been investigated in a chloride-laden environment under constant chlorides ingress conditions for more than 50 years.

4. It has been shown that concrete quality, as measured by the apparent chlorides diffusion coefficient, has a more dramatic impact of chlorides ingress, and hence on corrosion rates, than the cover thickness.

5. Only a marginal corrosion rate reduction would be achieved by using stainless 304 instead of carbon steel whereas a substantial improvement would be achieved by using stainless 316 instead of stainless 304 or carbon steel.

\section{Acknowledgements}

The author would like to thank NSERC and ISIS Canada for their generous support.

\section{References}

[1] Munshi, S. \& Boulfiza, M. Effect of Cations and Carbonation on Chlorides Binding in Concrete. First International Structural Specialty Conference, ISSC-1, Calgary, Alberta, Canada, May 23-26, 2006. 
[2] Boulfiza, M. \& Munshi, S. A reactive transport model for carbonation and chlorides ingress in concrete. ISTC'06 International Symposium of Theoretical Chemistry, Algiers, June 12-15, 2006.

[3] Lichtner, P. C., Steefel, C. I. \& Oelkers, E. H.; (eds). Reactive transport in porous media. Reviews in Mineralogy, Vol. 34, Mineralogical Society of America.

[4] DeGiorgi, V.G. Corrosion basics and computer modeling. Naval Research Laboratory, Department of the Navy, Washington D. C. 203755000, U.S.A.

[5] Brebbia, C.A., DeGiorgi, V.G. \& Adey, R.A., (eds) Simulation of Electrochemical Processes. ELECTROCOR 2005. First International Conference on the Simulation of Electrochemical Processes, 2 - 4 May 2005, Cadiz, Spain.

[6] Taylor, H.F.W., Cement Chemistry, 2nd edition, Thomas Telford, London, 1997.

[7] Broomfield, J.P. Corrosion of Steel in Concrete: Understanding, Investigation and Repair. Taylor \& Francis; $2^{\text {nd }}$ edition 2007. 